\title{
Impact of wastewater application on magnetic susceptibility in Terric Histosol soil
}

\author{
Zofia Sokołowska ${ }^{1}$ Andrey Alekseev ${ }^{2}$,Kamil Skic ${ }^{1 *}$, and Małgorzata Brzezińska ${ }^{1}$ \\ ${ }^{1}$ Institute of Agrophysics, Polish Academy of Sciences, Doświadczalna 4, 20-290 Lublin, Poland \\ ${ }^{2}$ Institute of Physicochemical and Biological Problems in Soil Science, Russian Academy of Sciences, Pushchino, \\ Moscow Region, 142290 Russia
}

Received June 8, 2015; accepted November 25, 2015

\begin{abstract}
A b s tr a c t. In this work, we attempted to analyse the changes in magnetic susceptibility in Terric Histosol soil irrigated with municipal wastewater in a period of four years. Effects of different plants (poplar and willow), wastewater doses, depths, as well as the concentration of the elements and the total carbon content were tested. The study showed that systematic wastewater irrigation diminished magnetic susceptibility values in the top layer of soil. However, statistical analysis revealed that both doses of wastewater and growing plants did not have a significant impact on the magnetic susceptibility of obtained results. Magnetic susceptibility decreased significantly with the depth, in accordance with higher total carbon and lower content of magnetic particles. High correlation coefficients were found between magnetic susceptibility and $\mathrm{Zn}, \mathrm{Al}_{2} \mathrm{O}_{3}, \mathrm{Fe}_{2} \mathrm{O}_{3}, \mathrm{MnO}$ content, whereas no correlation was observed for $\mathrm{Cr}$, as well as for $\mathrm{Pb}$.

$\mathrm{K}$ e y w o r d s: wastewater irrigation, magnetic susceptibility, total carbon, heavy metals
\end{abstract}

\section{INTRODUCTION}

Presence of magnetic minerals in soils may be inherited from the parent rocks (lithogenic origin), be related to pedogenesis processes (pedogenic origin), or could result from anthropogenic activities (Baghdadi et al., 2011; Boyko et al., 2004). Minerals such as magnetite and maghaemite are classified as ferromagnetics that strongly affect the value of magnetic susceptibility (Aleeksev et al., 2002; Lu et al., 2012b). Examples of paramagnetic minerals are biotite and pyrite. Their magnetic properties are caused by the presence of iron and manganese ions (Dearing, 1999). Goethite and hematite have antiferromagnetic properties (Strzyszcz et al., 1994), while quartz, chalk, calcium carbonate, and orthoclase are diamagnetic minerals (Dankoub et al., 2012).

*Corresponding author e-mail: kskic@ipan.lublin.pl
Non-mineral diamagnetic substances present in soil include organic matter, water, and plants with negative or weak magnetic susceptibility.

Anthropogenic contribution to magnetic susceptibility is a predominant factor in the organic layers of top soils (Schibler et al., 2002). Up to now, magnetic susceptibility measurements have been widely used to evaluate the spatial distribution of pollutants (Lu et al., 2008) in the upper layers of soil in industrial areas (Blundell et al., 2009; Duan et al., 2010), close to roads (Baghdadi et al., 2011; Wawer et al., 2015), and in marine and river sediments (Chan et al., 1998; Chaparro et al., 2011; Prajith et al., 2015; Zan et al., 2015). Several studies showed a strong correlation between magnetic parameters and the content of heavy metals (Karimi et al., 2011; Ma et al., 2015; Rosowiecka and Nawrocki, 2010; Strzyszcz and Magiera, 1998). However, it is still difficult to explain the mechanisms of these correlations in detail because they depend on a variety of complex and coactive physicochemical, pedological, or environmental factors (Lu et al., 2012a; Zawadzki et al., 2009).

Irrigation with municipal wastewater (WW) is considered to be an environmentally sound wastewater disposal practice compared to its direct disposal to the surface or ground water bodies. It can resolve certain environmental problems mainly related to an excessive or unbalanced supply of nutrients and the introduction of pollutants to ground water. In fact, not only biogenic substances retained in wastewater as residuals, but also a large amount of water can be recycled. On the other hand, continued irrigation may alter soil microbial activity and soil physicochemical characteristics, including changes in magnetic properties,

(C) 2016 Institute of Agrophysics, Polish Academy of Sciences 
organic matter, and heavy metal content. Accumulation of undesirable chemical constituents has potential to restrict some soil functions and cause plant toxicity and food chain contamination.

The purpose of this paper is to analyse changes in magnetic susceptibility in Terric Histosol soil irrigated with municipal wastewater for 4 years. Effects of different plant, wastewater doses, depths as well as concentrations of the elements and total carbon content are tested.

\section{MATERIALS AND METHODS}

The experiment sites were situated in the vicinity of a Wastewater Sewage Treatment plant in Lublin (South-East Poland). At this location, soil was classified as a peatmuck (Terric Histosol), according to the FAO classification. The basic soil properties were as follows: organic matter (OM) content 30.3-47.9\%; pH 7.80-9.13 (in $\mathrm{CaCl}_{2}$ ); bulk density $0.307-0.627 \mathrm{mg} \mathrm{m}^{-3}$ (Brzezińska et al., 2011). The experimental area was divided into two plots of 1 hectare area. Each of them was planted with poplar (Populus nigra and Populus alba - plot 1) and willow (Salix viminalis and Salix Americana - plot 2) and then divided into three subplots (A, B, and C). The first subplot was marked as a control and received only natural precipitation. Subplots $\mathrm{B}$ and $\mathrm{C}$ were irrigated with municipal wastewater in two doses $(60$ and $120 \mathrm{~mm})$. Irrigation was performed ten times in the vegetation period for four years. The value of the dose was established in accordance with the requirements of plants for nutrients $(\mathrm{N}, \mathrm{P}, \mathrm{K})$ and water availability. The wastewaters were obtained after two-step mechanical and biological treatment. The main characteristics of wastewater $\left(\mathrm{g} \mathrm{m}^{-3}\right)$ included: chemical oxygen demand (COD) 30.1-56.3; biological oxygen demand $\left(\mathrm{BOD}_{5}\right)$ 8.322.6; ${\mathrm{N}-\mathrm{NH}_{4}^{+}}^{+}$1.0-7.1; $\mathrm{N}^{-\mathrm{NO}_{3}^{-}}$20.2-38.4; $\mathrm{N}_{\text {tot }}$ 22.3-43.6;

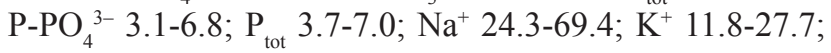
$\mathrm{Ca}^{2+} 59.7-95.2 ; \mathrm{Mg}^{2+} 12.6-19.7 ; \mathrm{SO}_{4}^{2-} 43.6-116.3 ; \mathrm{Cl}^{-} 67.8-$ 121.6; Zn 0.018-0.800; Cu 0.006-0.198; Pb 0.007-0.096 (Kotowski et al., 1999), and $\mathrm{pH}$ in the range of 6.5-8.4. Soil samples were taken from the depths of 0-10, 10-30, $30-50$, and $50-70 \mathrm{~cm}$, three years after the period of wastewater application. Three places of sampling located on each subplot were chosen randomly. Before analysis visible fractions of roots and mesofauna were removed. The soil was air-dried and sieved through a $2 \mathrm{~mm}$ mesh.

The elemental analyses were performed using a desktop XRF crystal diffraction scanning spectrometer SPECTROSCAN MAKC-GV1 (Alekseeva et al., 1999). The concentrations of $\mathrm{Cr}, \mathrm{Zn}, \mathrm{Pb}, \mathrm{MnO}, \mathrm{Fe}_{2} \mathrm{O}_{3}$, and $\mathrm{Al}_{2} \mathrm{O}_{3}$ were investigated. The quantitative analysis method was based on 12 standard soil calibration samples and then optimized using a computer simulation program.

The magnetic susceptibility (MS) was studied using the Kappabridge KLY-2 (Alekseev et al., 2002).
Total carbon content $\left(\mathrm{C}_{\text {tot }}\right)$ was determined by combustion of samples under an oxygen atmosphere at $1250^{\circ} \mathrm{C}$. A TOC MULTI N/C 2000, HT 1300 (Analytic Jena) device was used.

Statistical analysis was performed using Statistica 10.0 (StatSoft, Inc., Tulsa, USA). One-way analysis of variance (ANOVA) and post-hoc analysis (HSD Tukey test) were performed to test the influence of three factors (dose, depth, and plant) independently for the measured MS values. The F-value distribution was used to test the variance of magnetic susceptibility. Moreover Pearson correlation coefficients between means of MS values, heavy metal concentrations, and total carbon content were also determined. The significance level was evaluated at $\mathrm{p}<0.05$.

\section{RESULTS AND DISCUSSION}

The concentration of heavy metals is presented in Table 1. Chemical analyses showed that the concentration of $\mathrm{Zn}$ decreased in the soil profile. The greatest quantity of the metal was noticed for the high doses of sewage -75.5 and $71.5 \mathrm{mg} \mathrm{kg}^{-1}$, respectively, for the plots planted with poplar and willow. In contrast to $\mathrm{Zn}$, the concentrations of $\mathrm{Cr}$ and $\mathrm{Pb}$ were homogeneous with no effect of the doses and plants. The average values of the $\mathrm{Cr}$ content oscillated between 55.8 and $44.1 \mathrm{mg} \mathrm{kg}^{-1}$ and in the case of $\mathrm{Pb}$ from 108.3 to $59.3 \mathrm{mg} \mathrm{kg}^{-1}$.

The content of metal oxides is presented in Table 2. The amount of $\mathrm{Fe}_{2} \mathrm{O}_{3}$ and $\mathrm{Al}_{2} \mathrm{O}_{3}$ decreased in the soil profile, irrespective of the wastewater dose. However, it slightly diminished for the plots with poplar. In the case of $\mathrm{MnO}$, both doses of WW significantly affected the oxide content. The highest average value $\left(1503 \mathrm{mg} \mathrm{kg}^{-1}\right)$ was obtained in the control plot planted with willow at the depth of $0-10 \mathrm{~cm}$. The lower dose caused a decrease by $51 \%$ whereas the higher dose - by about $47 \%$ within the same layer. The same effect was observed for the plots planted with poplar. The average value of $\mathrm{MnO}$ decreased by 58 and $38 \%$ for the low and high doses, respectively. At the depth of $30-70 \mathrm{~cm}$, the concentration of $\mathrm{MnO}$ ranged from 631 to $397 \mathrm{mg} \mathrm{kg}^{-1}$ and was similar for all plants and doses. The decrease observed in the $\mathrm{MnO}$ content may be related to the fact that $\mathrm{Mn}$ is relatively mobile in organic soils, due to the weak bonding with soil OM (Kabata-Pendias and Pendias, 1999). Moreover, a small amount of clay minerals present in the investigated soil may cause low absorption of $\mathrm{Mn}$ into their crystal lattice or adsorption on exchange sites (Bradl, 2004). Therefore, higher elution of $\mathrm{Mn}$ in top layers might occur during wastewater irrigation.

Within the investigated area, the highest values of MS were observed for the top layer of soil and decreased values with increasing soil depth. This difference can be explained by the higher content of iron oxides in the top layer of the soil. A high concentration of ferrimagnetics was found in the top soil Of (fermentation) and Oh (humic) horizons (Zawadzki 
T a b l e 1. Contents of heavy metals in Terric Histosol soil under poplar and willow

\begin{tabular}{|c|c|c|c|c|c|c|c|c|c|}
\hline \multirow{2}{*}{$\begin{array}{l}\text { Depth } \\
(\mathrm{cm})\end{array}$} & \multicolumn{3}{|c|}{$\mathrm{Cr}$} & \multicolumn{3}{|c|}{$\mathrm{Zn}$} & \multicolumn{3}{|c|}{$\mathrm{Pb}$} \\
\hline & Control & Low & High & Control & Low & High & Control & Low & High \\
\hline \multicolumn{10}{|c|}{ Soil planted with poplar } \\
\hline \multirow{2}{*}{10} & 55.8 & 48.7 & 55.0 & 62.9 & 52.1 & 75.0 & 74.5 & 66.9 & 87.3 \\
\hline & $(5.3)$ & $(4.5)$ & $(5.0)$ & $(4.2)$ & (3.6) & $(4.0)$ & (16.4) & (14.6) & (15.6) \\
\hline \multirow{2}{*}{30} & 48.4 & 53.6 & 49.6 & 48.1 & 39.1 & 31.6 & 105.1 & 86.8 & 81.4 \\
\hline & $(5.1)$ & $(5.0)$ & $(5.4)$ & $(4.0)$ & (3.8) & $(4.3)$ & (16.5) & $(16.2)$ & (17.8) \\
\hline \multirow{2}{*}{50} & 53.1 & 54.1 & 43.1 & 27.7 & 26.0 & 33.9 & 100.7 & 108.3 & 75.9 \\
\hline & $(5.1)$ & $(5.5)$ & $(5.4)$ & $(3.9)$ & $(4.4)$ & $(4.4)$ & $(16.7)$ & $(18.4)$ & $(18.1)$ \\
\hline \multirow{2}{*}{70} & 52.7 & 55.8 & 45.7 & 34.2 & 34.2 & 29.7 & 86.8 & 105.5 & 86.0 \\
\hline & $(5.0)$ & $(5.0)$ & $(5.4)$ & $(3.9)$ & $(3.8)$ & $(4.4)$ & $(16.5)$ & (16.2) & $(18.6)$ \\
\hline \multicolumn{10}{|c|}{ Soil planted with willow } \\
\hline \multirow{2}{*}{10} & 47.6 & 52.4 & 53.9 & 67.5 & 50.6 & 71.5 & 77.4 & 92.2 & 59.3 \\
\hline & $(5.0)$ & $(4.8)$ & $(5.9)$ & $(4.1)$ & (3.7) & $(4.7)$ & (15.9) & (14.6) & (18.3) \\
\hline \multirow{2}{*}{30} & 42.2 & 51.7 & 50.0 & 34.5 & 49.7 & 32.7 & 82.5 & 83.3 & 72.7 \\
\hline & $(6.0)$ & $(5.0)$ & $(5.1)$ & $(4.9)$ & (3.8) & (3.9) & $(20.2)$ & (15.2) & $(16.4)$ \\
\hline \multirow{2}{*}{50} & 41.7 & 55.4 & 47.7 & 35.0 & 42.3 & 25.0 & 78.0 & 105.9 & 89.5 \\
\hline & (5.3) & $(5.4)$ & $(4.9)$ & $(4.4)$ & (4.2) & (3.9) & (18.0) & (17.4) & (16.3) \\
\hline \multirow{2}{*}{70} & 41.1 & 50.5 & 54.1 & 21.5 & 26.9 & 40.4 & 74.9 & 101.9 & 76.3 \\
\hline & (3.9) & $(5.1)$ & $(5.0)$ & (3.3) & $(4.0)$ & (3.8) & (14.2) & (16.9) & $(16.0)$ \\
\hline
\end{tabular}

Average values with standard error in parenthesis.

et al., 2010). On the other hand, organic matter possesses diamagnetic properties and affects weak and negative values of magnetic susceptibility (Dearing, 1999). The total carbon content slightly increased in the soil profile with no significant response to WW application with average values of $217 \mathrm{mg} \mathrm{g}^{-1}$. It is worth mentioning that the average values of MS for the control variants in the top layer of the soil were 19.7 and $18.410^{-8}$. Simultaneous wastewater application diminished the measured MS. In the case of the irrigated plots, the values oscillated between 5.6 and $11.710^{-8}$ (for poplar and willow, respectively). This effect was probably related to elution of some ferrimagnetic components together with the dissolved fraction of WW organic matter and with their movement through the soil profile (Lu et al., 2012b). The statistical analysis performed (one way ANOVA, at a level of significance 0.05) showed that the differences between the wastewater variants and plants were not statistically significant. The F-values were $0.69(\mathrm{p}=0.41)$ and $2.51(\mathrm{p}=0.09)$ for the plant and dose variant, respectively. However, it should be noticed that the value of $\mathrm{p}=0.09$ obtained for the effect of the dose is close to the given significance level. In this case, the relatively small number of samples used in statistical analysis may affect correct interpretation of the results. Therefore, for better understanding of the impact of wastewater dose variants on MS, as well as to avoid possible measurement errors, more repetitions are required. The depth had an influence on the magnetic parameter, especially in the layers of $0-10$ and $10-30 \mathrm{~cm}$ (F-values equalled 37.55 at $\mathrm{p}<0.05$ ). At the depth of $30-70 \mathrm{~cm}$, no differences between the MS values were observed (at $\mathrm{p}<0.05$ ). Deeper layers $(30-70 \mathrm{~cm})$ in the soil profile were represented through the lithogenic background of magnetic susceptibility and showed contribution to soil MS (Wang and Qin, 2005). At this depth, magnetic susceptibility is almost constant or varies slightly. In accordance with Hanesch and Scholger (2002), soil processes act within this layer while anthropogenic impacts are constrained to the upper horizons. 
T a b l e 2. Contents of $\mathrm{MnO}, \mathrm{Fe}_{2} \mathrm{O}_{3}$, and $\mathrm{Al}_{2} \mathrm{O}_{3}$ in Terric Histosol soil under poplar and willow

\begin{tabular}{|c|c|c|c|c|c|c|c|c|c|}
\hline \multirow{2}{*}{$\begin{array}{l}\text { Depth } \\
(\mathrm{cm})\end{array}$} & \multicolumn{3}{|c|}{$\mathrm{MnO}$} & \multicolumn{3}{|c|}{$\frac{\mathrm{Fe}_{2} \mathrm{O}_{3}}{\left(\mathrm{mg} \mathrm{kg}^{-1}\right)}$} & \multicolumn{3}{|c|}{$\mathrm{Al}_{2} \mathrm{O}_{3}$} \\
\hline & Control & Low & High & Control & Low & High & Control & Low & High \\
\hline \multicolumn{10}{|c|}{ Soil planted with poplar } \\
\hline \multirow{2}{*}{10} & 1040.3 & 436.5 & 645.2 & 1.9 & 1.0 & 1.4 & 5.3 & 3.8 & 5.0 \\
\hline & (21.96) & $(12.59)$ & (16.18) & $(0.02)$ & $(0.01)$ & $(0.02)$ & $(0.35)$ & $(0.28)$ & $(0.33)$ \\
\hline \multirow{2}{*}{30} & 925.9 & 463.2 & 520.2 & 1.4 & 0.7 & 0.8 & 4.6 & 3.2 & 3.4 \\
\hline & $(20.82)$ & (13.89) & $(15.81)$ & $(0.02)$ & $(0.01)$ & $(0.01)$ & $(0.34)$ & $(0.29)$ & $(0.31)$ \\
\hline \multirow{2}{*}{50} & 631.3 & 458.8 & 417.3 & 0.7 & 0.4 & 0.4 & 2.4 & 2.6 & 2.7 \\
\hline & $(16.65)$ & $(15.38)$ & $(14.60)$ & $(0.01)$ & $(0.01)$ & $(0.01)$ & $(0.28)$ & $(0.30)$ & $(0.31)$ \\
\hline \multirow{2}{*}{70} & 488.9 & 504.0 & 397.4 & 0.5 & 0.6 & 0.5 & 2.8 & 2.6 & 3.0 \\
\hline & (14.52) & (14.53) & (14.15) & $(0.01)$ & $(0.01)$ & $(0.01)$ & $(0.30)$ & $(0.28)$ & $(0.31)$ \\
\hline \multicolumn{10}{|c|}{ Soil planted with willow } \\
\hline \multirow{2}{*}{10} & 1502.9 & 731.7 & 791.9 & 2.1 & 2.2 & 1.8 & 4.8 & 6.5 & 5.9 \\
\hline & $(27.60)$ & (16.89) & $(20.29)$ & $(0.02)$ & $(0.02)$ & $(0.02)$ & $(0.33)$ & $(0.34)$ & $(0.38)$ \\
\hline \multirow{2}{*}{30} & 1111.1 & 681.9 & 530.6 & 0.9 & 2.1 & 0.9 & 3.0 & 6.7 & 3.6 \\
\hline & (26.29) & (16.80) & (15.14) & $(0.01)$ & $(0.02)$ & $(0.01)$ & $(0.35)$ & $(0.36)$ & $(0.31)$ \\
\hline \multirow{2}{*}{50} & 550.8 & 560.7 & 488.5 & 0.6 & 0.7 & 0.8 & 2.5 & 2.9 & 3.0 \\
\hline & (16.40) & (16.21) & (14.56) & $(0.01)$ & $(0.01)$ & $(0.01)$ & $(0.30)$ & $(0.32)$ & $(0.29)$ \\
\hline \multirow{2}{*}{70} & 568.5 & 426.5 & 435.1 & 0.9 & 0.5 & 0.9 & 2.5 & 2.3 & 3.7 \\
\hline & $(12.85)$ & (13.98) & $(13.40)$ & $(0.01)$ & $(0.01)$ & $(0.01)$ & $(0.20)$ & $(0.28)$ & $(0.30)$ \\
\hline
\end{tabular}

Average values with standard error in parenthesis.

The plots presented in Fig. 1 show correlations between magnetic susceptibility and the content of total carbon, heavy metals, and oxides of $\mathrm{Mn}, \mathrm{Fe}$, and $\mathrm{Al}$, as well as the regression equations for each pair. The Pearson correlation coefficients were calculated for all samples as a single group including all depths.

The total carbon content showed a negative relation with MS $(R=-0.46, p<0,05)$ and this could reflect the distribution of organic matter in the soil profile. Organic matter is mentioned among the natural factors that can induce a decrease in magnetic susceptibility (Thompson and Oldfield, 1986).

Linear and positive correlations were confirmed for $\mathrm{Zn}$ $(\mathrm{R}=0.75, \mathrm{p}<0.05), \mathrm{MnO}, \mathrm{Fe}_{2} \mathrm{O}_{3}$, and $\mathrm{Al}_{2} \mathrm{O}_{3}(\mathrm{R} \geq 0.76, \mathrm{p}<0.05)$. The high correlation is associated with the presence of ferromagnetic components in the soil, especially the crystalline iron oxides, for which the greatest correlation was observed $(\mathrm{R}=0.89, \mathrm{p}<0.05)$. These components are common in the soil, but they can have an anthropogenic origin.
In accordance with previous study (Duan et al., 2010), the high correlation between MS and heavy metals like Zn, $\mathrm{Pb}$, and $\mathrm{Cu}$ can be attributed to the absorption into ferrimagnetic minerals, already present in the environment. In the solute form, these metals show similar chemical properties and have a tendency to co-precipitate with hydrous oxides of $\mathrm{Fe}$ and Mn (Chan et al., 1998; Wang and Qin, 2005). On the other hand, no correlations were observed between MS and $\mathrm{Cr}(\mathrm{R}=0.17, \mathrm{p}<0.05)$ and $\mathrm{Pb}(\mathrm{R}=-0.20, \mathrm{p}<0.05)$. $\mathrm{Cr}$ did not show an anthropogenic increase. This element should be treated as a common factor with distributions in the soil being lithologically controlled (Dankoub et al., 2012; Huliselan et al., 2010). No correlation between $\mathrm{Pb}$ and MS was observed by other authors (Gelisli and Aydin, 1998; Schmidt et al., 2005). However, the cause of such weak dependence could be the small number of replicates as well as the combination of samples from four analysed depths. 

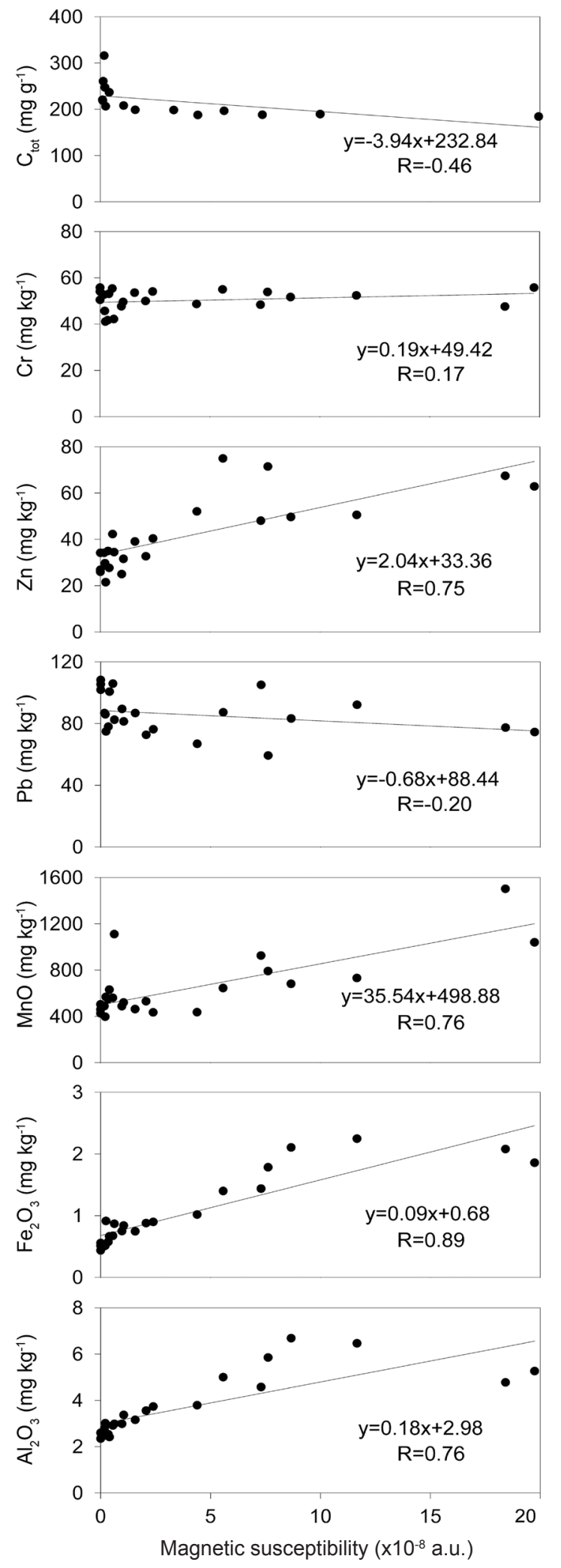

Fig. 1. Scatter plots and regression equations between magnetic susceptibility and $\mathrm{C}_{\text {tot }}, \mathrm{Cr}, \mathrm{Zn}, \mathrm{Pb}, \mathrm{MnO}, \mathrm{Fe}_{2} \mathrm{O}_{3}, \mathrm{Al}_{2} \mathrm{O}_{3}$ content. Pearson correlation coefficients for each pairs were calculated for all samples collected in the studied area.

\section{CONCLUSIONS}

Magnetic susceptibility measurements are both fast and convenient and can be used to evaluate and monitor potential soil changes during wastewater irrigation. The main conclusions from this study are as follows:

1. Simultaneous wastewater application diminished the measured magnetic susceptibility Terric Histosol. However, statistical analysis showed that the differences between the wastewater variants and plants were not significant at $p=0.05$. The depth had also an influence on the magnetic parameter. The highest values of magnetic susceptibility were observed for the top layer of soil; they decreased when the soil depth increased.

2. Linear and positive correlations were confirmed for $\mathrm{Zn}(\mathrm{R}=0.75, \mathrm{p}<0.05)$ and all the studied oxides $(\mathrm{R} \geq 0.76$, $\mathrm{p}<0.05)$ with a negative relation for $\mathrm{C}_{\text {tot }}(\mathrm{R}=-0.46, \mathrm{p}<0.05)$. No correlation between magnetic susceptibility and $\mathrm{Cr}$ and $\mathrm{Pb}$ was observed. The number of replicates as well as the combination of samples from all depths could affect the Pearson correlations coefficient obtained.

3. The manganese oxide content decreased significantly after wastewater application. This is connected with the high mobility of $\mathrm{MnO}$, its weak binding with soil organic matter, as well as the small amount of clay minerals in the investigated soil.

\section{REFERENCES}

Alekseev A., Alekseeva T., Sokołowska Z., and Hajnos M., 2002. Magnetic and mineralogical properties of different granulometric fractions in the soils of the Lublin Upland region. Int. Agrophysics, 16, 1-6.

Alekseeva T., Alekseev A., Sokołowska Z., and Hajnos M., 1999. Relationship between mineralogical composition and physical properties of soils. Eurasian Soil Sci., 32, 548-557.

Baghdadi M. El., Jakani K., Barakat A., and Bay Y., 2011. Magnetic susceptibility and heavy metal contamination in agricultural soil of Tadla Plain. J. Materials Environ. Sci., 2, 513-519.

Blundell A., Hannam J.A., Dearing J.A., and Boyle J.F., 2009. Detecting atmospheric pollution in surface soils using magnetic measurements: A reappraisal using an England and Wales database. Environmental Pollution, 157, 2878-2890.

Boyko T., Scholger R., and Stanjek H. Magprox Team, 2004. Topsoil magnetic susceptibility mapping as a tool for pollution monitoring: repeatability of in situ measurements. J. Applied Geophysics, 55, 249-259.

Bradl H.B., 2004. Adsorption of heavy metal ions on soils and soils constituents. J. Colloid Interface Sci., 277, 1-18.

Brzezińska M., Sokołowska Z., Alekseeva T., Alekseev A., Hajnos M., and Szarlip P., 2011. Some characteristics of organic soils irrigated with municipal wastewater. Land Degradation Develop., 22, 586-595.

Chan L.S., Yeung C.H., Yim W.W-S., and Or O.L., 1998. Correlation between magnetic susceptibility and distribution of heavy metals in contaminated sea-floor sediments of Hong Kong Harbour. Environmental Geology, 36, 77-86. 
Chaparro M.A.E., Chaparro M.A.E., Rajkumar P., Ramasamy V., and Sinito A.M., 2011. Magnetic parameters, trace elements, and multivariate statistical studies of river sediments from southeastern India: a case study from the Vellar River. Environmental Earth Sci., 63, 297-310.

Dankoub Z., Ayoubi S., Khademi H., and Lu S.G., 2012. Spatial distribution of magnetic properties and selected heavy metals in calcareous soils as affected by land use in the Isfahan Region, central Iran. Pedosphere, 22, 33-47.

Dearing J., 1999. Environmental Magnetic Susceptibility: Using the Bartington MS2 System. Chi Publishing, Keniloworth, UK.

Duan X.M., Hu S.Y., Yan H.T., Blaha U., Roesler W., Appel E., and Sun W.H., 2010. Relationship between magnetic parameters and heavy element contents of arable soil around a steel company, Nanjing. Science China Earth Science, 53, 411-418.

Gelisli K. and Aydin A., 1998. Investigation of environmental pollution using magnetic susceptibility measurements. European J. Environ. Eng. Geophysics, 3, 53-61.

Hanesch M. and Scholger R., 2002. Mapping of heavy metal loadings in soils by means of magnetic susceptibility measurements. Environmental Geology, 42, 857-870.

Huliselan E.K., Bijaksana S., Srigutomo W., and Kardena E., 2010. Scanning electron microscopy and magnetic characterization of iron oxides in solid waste landfill leachate. J. Hazardous Materials, 179, 701-708.

Kabata-Pendias A. and Pendias H., 1999. Biogeochemistry of Trace Elements (in Polish). PWN Press, Warsaw, Poland.

Karimi R., Ayoubi S., Jalalian A., Sheikh-Hosseini A.R., and Afyuni M., 2011. Relationships between magnetic susceptibility and heavy metals in urban topsoils in the arid region of Isfahan, central Iran. J. Applied Geophysics, 74, 1-7.

Kotowski M., Stępniewska Z., Saczuk M., Kotowska U., and Pasztelan M., 1999. Effluent of municipal sewages irrigation of industrial cultivation on the level of biogens concentration in the soil and drainage waters (in Polish). Acta Agrophysica, 22, 93-113.

Lu S.G., Bai S.Q., and Fu L.X., 2008. Magnetic properties as indicators of $\mathrm{Cu}$ and $\mathrm{Zn}$ contamination in soils. Pedosphere, $18,479-485$.

Lu S.G., Chen D.J., Wang S.Y., and Liu Y.D., 2012a. Rock magnetism investigation of highly magnetic soil developed on calcareous rock in Yun-Gui Plateau, China: Evidence for pedogenic magnetic minerals. J. Applied Geophysics, 77, 39-50.

Lu S.G., Zhu L., and Yu J-Y., 2012b. Mineral magnetic properties of Chinese paddy soils and its pedogenic implications. Catena, 93, 9-17.
Ma M., Hu S., Cao L., Appel E., and Wang L., 2015. Atmospheric pollution history at Linfen (China) uncovered by magnetic and chemical parameters of sediments from a water reservoir. Environ. Pollution, 204, 161-172.

Prajith A., Rao V.P., and Kessarkar P.M., 2015. Magnetic properties of sediments in cores from the Mandovi estuary, western India: Inferences on provenance and pollution. Marine Pollution Bulletin, 99, 338-345.

Rosowiecka O. and Nawrocki J., 2010. Assessment of soils pollution extent in surroundings of ironworks based on magnetic analysis. Studia Geophysica et Geodaetica, 54, 185-194.

Schibler L., Boyko T., Ferdyn M., Gajda B., Höll S., Jordanova N., and Rösler W. Magprox Team, 2002. Topsoil magnetic susceptibility mapping: data reproducibility and compatibility, measurement strategy. Studia Geophysica et Geodaetica, 46, 43-57.

Schmidt A., Yarnold R., Hill M., and Ashmore M., 2005. Magnetic susceptibility as proxy for heavy metal pollution: a site study. J. Geochemical Exploration, 85, 109-117.

Strzyszcz Z. and Magiera T., 1998. Magnetic susceptibility and heavy metals contamination in soils of southern Poland. Physics and Chemistry Earth, 23, 1127-1131.

Strzyszcz Z., Magiera T., and Bzowski Z., 1994. Magnetic susceptibility as indicator of soils contamination in some regions of Poland. Soil Sci. Annual Suppl., 44, 85-93.

Thompson R. and Oldfield F., 1986. Environmental Magnetism. Allen and Unwin, London, UK.

Wang X.S. and Qin Y., 2005. Correlation between magnetic susceptibility and heavy metals in urban topsoil: a case study from the city of Xuzhou, China. Environ. Geology, 49, 10-18.

Wawer M., Magiera T., Ojha G., Appel E., Bućko M.S., and Kusza G., 2015. Characteristics of current roadside pollution using test-monitoring plots. Sci. Total Environ., 505, 795-804.

Zan J., Fang X., Yan M., Zhang Z., and Zhang D., 2015. Regional variations in magnetic properties of surface sediments in the Qaidam Basin and their paleoenvironmental implications. J. Applied Geophysics, 122, 86-93.

Zawadzki J., Magiera T., and Fabijańczyk P., 2009. Geostatistical evaluation of magnetic indicators of forest soil contamination with heavy metals. Studia Geophysica et Geodaetica, 53, 133-149.

Zawadzki J., Fabijańczyk P., Magiera T., and Strzyszcz Z., 2010. Study of litter influence on magnetic susceptibility measurements of urban forest topsoils using the MS2D sensor. Environ. Earth Sci., 61, 223-230. 